\title{
The Challenge of Regulating Private Wildlife Ranches for Conservation in South Africa
}

\author{
$\underline{\text { Jenny A. Cousins }}^{1}$, Jon P. Sadler ${ }^{2}$, and James Evans ${ }^{1}$
}

\begin{abstract}
We address the new attempts at regulating wildlife ranches on private land in South Africa. Although positive conservation impacts can be attributed to private wildlife ranching, there are a number of ecological consequences that often arise as a result of economic priorities. We present and analyze new national regulations aimed at coordinating provincial legislation and guiding the wildlife industry in a more conservationist direction, and examine tensions that have arisen between different sociopolitical scales as a result. Data were obtained through a desk-based study of legal documents and interviews with key stakeholders. The new regulations begin to address international obligations and national policy on biodiversity conservation by potentially combating a number of specific ecological problems associated with wildlife ranching. However, in practice, the regulations are a significant source of tension among stakeholders and will be challenging to implement. A key issue is competing agendas between incentivedriven ranchers and conservationist aims. It may be that in addressing the ecological problems at the margin, the new regulations will encourage some ranchers to convert their land away from conservation friendly land use.
\end{abstract}

Key Words: conservation regulation; private wildlife ranches; South Africa; stakeholder views

\section{INTRODUCTION}

Here, we address new attempts in South Africa to regulate wildlife ranches on private land. This is a major enterprise with more than 10,000 wildlife ranches and some 4,000 mixed wildlife/livestock enterprises (Hearne and McKenzie 2000, Bothma 2002, Amalgamated Banks of South Africa 2003, Bothma et al. 2009). Private landholders have played an important role in national conservation efforts (Child 2009) in a country that, according to Bothma et al. (2009), is "the scene of one of the greatest reversals of fortune ever seen in wildlife conservation." In South Africa in the $19^{\text {th }}$ century, wildlife was devastated by early European settlers (MacKenzie 1988, Adams and McShane 1996, Neumann 1996, Adams and Mulligan 2003, King 2007, Carruthers 2008). In the $20^{\text {th }}$ century, wildlife was exterminated to make way for livestock at a time when wildlife was perceived to conflict with livestock (Carruthers 2008, Bothma et al. 2009). By 1950, wildlife had been severely decimated outside of South Africa's national parks (Bothma et al. 2009). Since this time, wildlife on private land has shown considerable growth, and it has been estimated that wildlife utilization enterprises now cover some $16.8 \%$ of South Africa, compared with provincial and national protected areas that cover roughly $6.1 \%$ (Bothma and Von Bach 2009, as cited in Bothma et al. 2009). Managing state areas designated for biodiversity conservation is expensive, and securing long-term funding to maintain conservation initiatives is a challenging issue (Harris 2004) as budgets for park management diminish in many provinces because of constant pressure from other political priorities (Botha 2001, Krug 2002, Scriven and Eloff 2003, Leader Williams et al. 2005). As such, responsibility for conservation in South Africa is increasingly becoming a private land issue (Botha 2001, Krug 2002, Scriven and Eloff 2003).

Although positive conservation impacts such as maintaining "natural" or semi-natural habitat and providing resources and land for species introduction programs are attributed to private wildlife ranches, there are a number of practices within the ranching industry today that conflict with 
conservation principles, including: (1) deliberate cross-breeding or hybridization of different species and subspecies, (2) deliberate breeding of recessive colour variations in game, (3) selective breeding of animals for trophy hunting, (4) unscientific intensive captive breeding programs that can lead to inbreeding of rare game species and when released into extensive systems can cause genetic pollution of wild populations, extinction of subspecies, and the spread of disease and parasites, (4) introduction of extralimital species that can lead to hybridization, degradation of habitat, low survival rates of some introduced species, and displacement of indigenous species, (5) introduction of invasive alien species, (6) conversion of veld through burning and cutting, and (7) predator persecution, to protect game (Green and Rothstein 1998, Bigalke 2000, Castley et al. 2001, Smith and Wilson 2002, Hall-Martin and Castley 2003, Boone and Hobbs 2004, Hamman et al. 2005, Lindsey et al. 2005, Steenkamp et al. 2005, Langholz and Kerley 2006, Lindsey et al. 2006, Cousins et al. 2008, Child 2009). The legal requirement for wildlife utilization systems to be surrounded by game fencing has led to fragmented landscapes, causing genetic isolation of species and the disruption of migratory routes. These problems are in addition to overstocking and land degradation (Bothma et al. 2009, Lindsey et al. 2009). Furthermore, many ranches are too small to contain genetically healthy predator populations.

Such practices, often driven by financial gain, appear to make little contribution to biodiversity conservation, and could result in the significant depletion of the genetic integrity and diversity of natural populations (Department of Environmental Affairs and Tourism 2005). In addition, the breeding and reintroduction of species is often limited to a small variety of popular species (Cousins et al. 2008) and stocking large numbers, or even just the presence, of species such as lion (Panthera leo) and elephant (Loxodonta africana) can have a detrimental effect on biodiversity. Other reported problems within the industry include: (1) hunting, contravening the humane treatment of animals and/ or the principles of fair-chase such as hunting with dogs, the use of traps, the use of poison, bow hunting, "green" hunting, and "canned" hunting, and (2) the hunting of "damage-causing" individuals (Department of Environmental Affairs and Tourism 2005). In a recent study of stakeholder perspectives, fundamental limitations identified by respondents included bias toward business objectives over conservation, a lack of scientific management of ranches, and an inadequate knowledge of conservation ecology (Cousins et al. 2008). Indeed, ranches are businesses first and foremost, competing to attract customers. The differences in legislation and regulations between the provinces is also problematic (Bothma et al. 2009), resulting in a complex and fragmented system that is largely outdated, inconsistent, and lacking national norms and standards (Bürgener at al. 2001, Wynberg 2002, Bürgener et al. 2005). There are inconsistencies between provincial permit-award procedures, the conservation status of many indigenous species, and the extent to which extralimital translocation can occur. Furthermore, this system does not provide a structure to monitor wildlife at a national level (Bürgener et al. 2001). In addition to these problems, the level of transformation within the hunting community for previously disadvantaged individuals is reported to be extremely low (Department of Environmental Affairs and Tourism 2005).

In a bid to "scale up" the management of the wildlife industry, which is an industry that has rapidly expanded and developed in a rather piecemeal or organic fashion ahead of regulation, new national regulations have been developed with the aim of coordinating provincial legislation and guiding the industry in a more conservationist direction. We chart the development of these regulations, present and analyze their significance for conservation, and examine the tensions that have arisen among different sociopolitical scales as a result. We conclude by considering the major strengths and weaknesses of the regulations and their suitability as an approach to conservation. There are two main forms of private wildlife production systems: extensive and intensive. We focus largely on the extensive system, that is, the managed extensive production of free-living animals on large, primarily fenced areas of private or communal land, usually for the purposes of hunting, live-game sales, trophy hunting, wildlife meat, or tourism (Bothma 2002).

\section{Private Wildlife Ranching: Historical Development}

Current approaches to the regulation of wildlife ranching in Africa are perhaps best contextualized through the lens of history (Jones 2006). Much of the recent literature on the history of conservation and wildlife ranching in South Africa is provided in 
reviews by Child (2009), Bothma et al. (2009), and a detailed paper by Carruthers (2008). According to Bothma et al. (2009), much of the initial stimulus for wildlife ranching reflected the personal desires of landowners and investors to provide a "retreat" for personal enjoyment; however, over time, motivations have diversified and include conservation, profit, and the sustainability of wildlife production compared with conventional agriculture. Many of the factors that have made the establishment of private wildlife utilization enterprises attractive have their roots in political and legal developments (Bothma et al. 2009), including: (1) the decline in agricultural subsidies and deregulation of the agricultural sector, (2) the Game Theft Act of 1991 which combated theft and illegal hunting and capture, and gave rights of ownership of wildlife on suitable fenced land, and (3) changes to the Shareblock Act, legislation regarding conservancies, biospheres, and other protected areas, and new labour laws have all encouraged the transformation from conventional agriculture to wildlife utilization (Carruthers 2008, Bothma et al 2009). Other important factors include: (1) changing views on the need to separate wild animals and domestic stock, (2) changing ideas around nature and environmental conservation, wildlife management, and sustainable development, (3) the sharing of expertise among wildlife managers in state protected areas and on private farmland, and (4) the need for increased levels of protein production for a growing human population (Carruthers 2008). A further incentive has been the growth in international wildlife tourism (Bothma et al 2009).

In certain environments, wildlife ranching has an economic comparative advantage and "astute policy that devolves rights to landholders and that encourages value-adding uses of wildlife, including trade, is necessary to translate this theoretical advantage into wildlife conservation and economic growth" (Child 2009). In recent years, there has been increasing interest in market-based approaches to conservation, the rationale being that creating incentives for landowners and managers causes them to behave in a way that sustains environmental functions. The success of conservation on these lands is based on the price-proprietorshipsubsidiarity hypothesis (Child 2003, 2005) that says: (1) if wildlife is valuable, (2) if this value is captured by landholders, and (3) if rights to manage wildlife are organized at a local level, then renewable resources are likely to be husbanded better and ultimately conserved. This hypothesis lies at the heart of the paradigm of sustainable use and provides a useful theoretical backdrop with which to analyze the new regulations.

\section{METHOD}

There are two stages to the research design: (1) a desk-based study of legal documents, and (2) interviews with stakeholders involved in wildlife ranching and conservation. The desk-based study made use of the Department of Environmental Affairs' website where legal documents, reports, and forthcoming regulations can be found. The second stage of the research design involved a qualitative approach to access the knowledge and opinions of those involved in the development and implementation of national legislation, those directly affected by the legislation, and those involved in encouraging conservation of private wildlife ranches. Semistructured interviews (Dunn 2005, Fontana and Frey 2005, Longhurst 2005, Marshall and Rossman 1995) were conducted with key actors involved in: (1) national and provincial governments, (2) conservation NGOs, and (3) the wildlife-ranching industry. Research was carried out between autumn 2006 and winter 2007, including a total of 4.5 months in South Africa. A number of interviews were conducted via telephone and email.

Actors include key representatives from the Department of Environmental Affairs' Biodiversity and Conservation branch, the provincial governmental departments dealing with nature conservation, the South African National Biodiversity Institute (SANBI), the game-ranching industry, nongovernmental South African conservation organizations, and stewardship programs. There were 41 respondents in total. Of these, nine were from within the government, 14 from conservation NGOs, and 18 within the wildlife-ranching industry. A number of persons within the provincial government departments did not wish to participate, largely because of feelings of not knowing enough about private ranching and conservation. Nonetheless, the sample captures a representative reflection of opinions from those involved in conservation and wildlife ranching in South Africa today. All interview data were transcribed and coded to identify key themes relating to the research area (Strauss and Corbin 1990, Cope 2005). We make use of selected anonymous excerpts from the interviews. 


\section{DEVELOPMENT OF THE REGULATIONS}

A combination of factors provided the impetus for the development of new national regulations. These included negative media reports on practices that were threatening the hunting industry's international reputation such as canned hunting, and the widespread perception that the industry was not adequately regulated and should be brought in line with South Africa's national and international obligations to conserve biodiversity (Department of Environmental Affairs and Tourism 2005). One such obligation is the White Paper on the Conservation and Sustainable Use of South Africa's Biological Diversity (Department of Environmental Affairs and Tourism 1997), the country's principal policy document on the use and conservation of biodiversity, following the themes of the Convention of Biological Diversity (CBD) (Wynberg 2002). The White Paper sets the stage for key pieces of legislation such as the Biodiversity Act, providing the legal basis for biodiversity management and allowing for the listing of protected, endangered, alien, and invasive species, and the setting of regulations with regard to listed species. Until recently, there was little development of these regulations.

In April 2005, the Minister of Environmental Affairs and Tourism appointed a panel of experts that included representatives from the hunting industry, the community, international and national conservation organizations, animal welfare organizations, and others to investigate hunting activities and to recommend guiding principles for the drafting of national norms and standards. In October 2005, the panel released a report (Department of Environmental Affairs and Tourism 2005) that also addressed some broader aspects related to the wildlife industry. The report was informed by public input and four commissioned research/review papers on: (1) the status quo of the hunting industry, (2) the regulation of the industry, (3) conservation impacts, and (4) international best practices for hunting. Public input came from various hunting and game associations, animal welfare organizations, international and national conservation NGOs, the Game Rangers Association of South Africa, community representatives, and representatives of the canned hunting industry. Three broad sets of principles guided the panel in their assessment: (1) the sustainable use of wildlife, seeking to ensure that any practices associated with hunting do not compromise the long-term survival and viability of a particular species or ecosystem, (2) the humane treatment of animals, as set out in South Africa's Animal Protection Act (1962), and (3) the principle of fair chase (Department of Environmental Affairs and Tourism 2005). The recommendations of this report contributed significantly to the development of the new Threatened and Protected Species Regulations (TOPS) (Department of Environmental Affairs and Tourism 2007b) These regulations came into force on the postponed date of 1 February 2008 after public feedback, amendment, and workshops. They also contributed significantly to the draft Alien and Invasive Species Regulations (AIS) (Department of Environmental Affairs and Tourism 2009b) that have direct consequences for the wildlife-ranching industry.

\section{SIGNIFICANCE FOR CONSERVATION}

The goal of the new TOPS regulations is to provide a national standard for the utilization of named threatened or protected species in both owned and wild populations across South Africa, on private, state, and communal land. According to a senior employee of the Regulation and Monitoring Services who is responsible for drafting and implementing the regulations, "TOPS provides additional protection in provinces where legislation is not adequate and also uniform protection in all nine provinces" (senior employee, national government/regulation and monitoring services, 2008 , personal communication). A wide range of critically endangered, endangered, vulnerable, and protected indigenous species of high conservation value or national importance, spanning fish, reptiles, birds, mammals, plants, and invertebrates, will have uniform conservation status across South Africa for the first time, including the African wild $\operatorname{dog}$ (Lycaon pictus), mountain zebra (Equus zebra), blue swallow (Hirundo atrocaerulea), roan antelope (Hippotragus equinus), bontebok (Damaliscus pygargus pygargus), oribi (Ourebia ourebi), spotted hyena (Crocuta crocuta), honey badger (Mellivora capensis), wild yam (Dioscorea ebutsiniorum), and cycad (Cycadophyta; see Department of Environmental Affairs and Tourism $2007 a$ for a full list). No restricted activities, including for example, possessing, killing, gathering, breeding, selling, or translocating, can be carried out involving a TOPS specimen, whether it is alive or dead, without a TOPS permit. 
These regulations will have a direct bearing on the permits issued by Nature Conservation and, therefore, will affect the running of private wildlife ranches across South Africa. Authorities will now have to consider a greater number of factors, such as biodiversity management plans for the species concerned (Appendix 1) when issuing a permit. Specifically, ranchers may be refused a permit if: (1) the application does not appear to be in the best interest of the threatened or protected species concerned, (2) the wildlife ranch to which the TOPS species is to be translocated falls outside of the natural distribution range of that species, and (3) there is a risk of spreading a disease or a risk of hybridization with other species on translocation of a TOPS species to an extensive wildlife system (Carroll and Boshoff 2007). Therefore, the regulations should reduce the risk of hybridization and unnecessary deaths of species not adapted to the environment in which they are introduced. For example, where blue wildebeest (Connochaetes taurinus) already occur on an extensive wildlife system, and the intention is to introduce the TOPS species black wildebeest (Connochaetes gnou) on the same extensive wildlife system, a permit for the translocation of the black wildebeest to the extensive wildlife system must be refused to prevent potential hybridization (Carroll and Boshoff 2007). Similarly, the TOPS species bontebok cannot be placed on a ranch where blesbok (Damaliscus dorcas phillipsi) are already present. The regulations should also reduce deliberate crossbreeding of TOPS species and inbreeding in captive breeding operations, and therefore the pollution of wild populations, through tighter restrictions on application for registration of an intensive breeding facilities and regular monitoring of practice. The problem of stocking a small number of isolated TOPS species should also be reduced through the permit-issuing system, in which issuing authorities have to assess whether the restricted activities are likely to have a negative impact on the survival of the species (TOPS regulation 10).

Under the new regulations, a permit is needed for restricted activities affecting wild transitory TOPS predators such as serval (Leptailurus serval), cheetah (Acinonyx jubatus), cape fox (Vulpes chama), and leopard (Panthera pardus). This will potentially reduce their persecution. However, these regulations do not apply to caracal (Caracal caracal) or black-backed jackal (Canis mesomelas), as they are not considered threatened species but are nonetheless frequently persecuted on ranches. An individual animal assessed by authorities to be "damage-causing" may be hunted with a TOPS permit as a last resort; however, a TOPS permit to hunt the animal may not be issued to a hunting client, in an attempt to reduce false claims. There are a number of stipulations in the regulations that are contrary to the recommendations of the panel of experts. Although the panel determined that using bait as a method of hunting compromises the principals of "fair chase" and thus recommended that it not be allowed, the regulations nonetheless allow the use of bait in hunting lions, hyena, and leopard. Similarly, the regulations do not prevent the use of flood or spotlights when hunting leopard and hyena. Damage-causing animals may be killed with the use of poison, bait, and traps, excluding gin traps. The regulations do not define "fair chase."

The second draft of the AIS regulations (Appendix 2) also incorporates regional restrictions, including activities relating to specific listed invasive indigenous mammal species (see Department of Environmental Affairs and Tourism 2009 $a$ for a full list) including giraffe (Giraffa camelopardalis), nyala (Tragelaphus angasii), waterbuck (Kobus ellipsiprymnus), and impala (Aepyceros melampus melampus). These regulations do not apply to indigenous species unless the species is a listed invasive species. Under these regulations, a large range of alien and invasive mammals, birds, reptiles, amphibians, fish, invertebrates, and plants species have various restrictions of use. There are three main categories of species. List 1 exempts various categories of alien species. List 2 lists prohibited alien species that cannot be imported and if found on a property require compulsory control, for example, Beisa oryx (Oryx beisa). List 3 provides listed invasive species under four categories: $(1 a)$ invasive species requiring compulsory control, for example, all hybrids and the lesser kudu (Tragelaphus imberbis), (1b) invasive species controlled as part of an invasive species program, for example, prickly pear (Opuntia, various subspecies), (2) invasive species regulated by area, for example, red river/spider/sugar gum (Eucalyptus, various species, (although $1 b$ within riparian areas), black-faced impala (Aepyceros melampus petersi), blesbok, red lechwe (Kobus leche), mountain reedbuck (Redunca fulvorufula), giraffe and impala, and (3) invasive species regulated by activity, for example, Derby eland (Tragelaphus derbianus).

For example if a rancher has nyala, a popular hunting species to be regulated by area, on their land, 
then his/her enclosure must either be within the distribution range of the species as determined by the Director-General, or the rancher must acquire a demarcation permit to undertake restricted activities such as possessing, selling, or hunting the nyala. A demarcation permit requires a risk assessment to be conducted at the cost of the rancher (Appendix 2). Such steps are seen as necessary to protect naturally occurring species from being displaced by invasive species. For example, nyala introduced in the Western Cape tend to displace bushbuck (Tragelaphus scriptus) (Department of Environmental Affairs and Tourism 2005). The regulations also have the potential to reduce hybridization of species such as blesbok and bontebok that are restricted by region. Furthermore, ranchers will no longer be able to undertake restricted activities involving hybrid species without a permit, for which a risk assessment is required. Where a listed invasive species occurs, all landowners will need to notify the relevant authority in writing. Some species are listed in both sets of regulations. For example, the endangered Hartmann's zebra (Equus zebra hartmannae) and the vulnerable Cape Mountain zebra (Equus zebra zebra) are TOPS species and indigenous invasive species with regional restrictions. As such, there should no longer be a threat of the subspecies hybridizing. The regulations have the potential to reduce the degradation of habitats that can occur through the presence of invasive and alien species, and also to reduce the conversion of natural veld into grassland with the purpose of introducing species not within their natural distribution range.

Most specific species reported in the literature as suffering ecological consequences as a result of ranching appear to be included in the regulations. However, one species that is not listed under either set of regulations is the springbok (Antidorcas marsupialis). Springbok introduced into the southern parts of the West Coast easily contract foot rot due to the humid winter conditions (Hamman et. al. 2003). There is also the threat of hybridization between the two springbok subspecies. Other shortcomings are found concerning the individual management of ranches. For example, according to a senior employee from the government branch responsible for drafting and implementing the regulations, "unfortunately, management of game farms without considering ecological concepts is a big problem, but it is not addressed in conservation legislation. The idea is that nature conservation departments should provide advice in this regard to landowners, but this happens in very few provinces" (senior employee, national government/regulation and monitoring services, 2008, personal communication). Other factors the regulations will not address are the inadequate knowledge of conservation ecology on many ranches, inappropriate carrying capacities and stocking rates for grazers and browsers, or inappropriate predator-prey ratios. Nor will they address the problems associated with game fencing small pockets of land, or the focus on popular species.

Both the TOPS regulations and the AIS regulations require that authorities gather and store specific information, such as the number of TOPS hunted each year, that should lead to greater species monitoring and feedback into a national system through collaboration with SANBI. The South African National Biodiversity Institute is responsible for the collection, analysis, coordination, and dissemination of information and operates as a national advisory body on biodiversity, among others such as the Endangered Wildlife Trust (EWT) and the World Wildlife Fund for Nature. The TOPS regulations require authorities to base their decisions to issue permits on any relevant information in the databases that $\mathrm{SANBI}$ is required to keep by the Biodiversity Act. The databases referred to in the Act are broad ranging (see section 11[j] of the Act) and include information on taxonomy, distribution, threat status, and known levels of use for different components of biodiversity. The South African National Biodiversity Institute is also responsible for determining hunting off-take limits, but according to a senior employee, this function is limited only to species identified by the Minister and is expected to comprise a small number of species of special concern. Although SANBI's role in terms of the wildlife-ranching industry is currently quite limited, they have an "ongoing commitment to develop these databases and to make them as comprehensive as possible" (senior employee, SANBI, 2007, personal communication).

The development of a national electronic permitting system will also assist in coordination. According to a senior employee of the division of Biodiversity and Conservation, "persons requiring a permit will apply online through a central system that has been developed to avoid duplication of permits, confusion, and corruption" (senior employee, national government/DEAT Directorate Biodiversity and Conservation, 2007, personal communication). Once adequately implemented and enforced, these 
regulations will assist in addressing South Africa's international obligations to the CBD, particularly those relating to sustainable use and alien species (see the Convention on Biological Diversity 2001 , articles 6(a), 8(c), 8(h), 8(k), 10(a), and 10(b); for example, "prevent the introduction of, control, or eradicate those alien species that threaten ecosystems, habitats or species" (article $8[\mathrm{~h}]$ ) and "adopt measures relating to the use of biological resources to avoid or minimize adverse impacts on biological diversity" (article 10[b]). They also address a number of national policy goals of the White Paper, for example: (1) conserving the diversity of landscapes, ecosystems, habitats, communities, populations, species and genes in South Africa, and (2) using biological resources sustainably and minimizing adverse impacts on biological diversity.

\section{STAKEHOLDER VIEWS}

Two key themes emerged from interviews: (1) the regulations are a considerable source of tension among stakeholders at a local, provincial, and national level, and (2) the economic priorities of ranchers conflict with conservationist aims.

\section{Tensions among Stakeholders}

There has been much discussion and disagreement regarding the content of TOPS regulations since their announcement, not only from the ranching community, but also from provincial governments and independent conservation organizations (Appendix 3). The national department developed the regulations for the provinces to implement and, although they were consulted in the development process, this scenario is perceived by some to cause problems. There are feelings from a number of individuals working in the provincial departments that they are better equipped in terms of experience to make management decisions regarding their province than the national body. They are also concerned about a lack of capacity and finances for implementation. The national body has serious concerns regarding the readiness of the provinces to implement the legislation in terms of manpower, knowledge, a lack of motivation to understand and implement the regulations, and also regarding cooperation because of a greater workload. They are also concerned that there is a lack of understanding by ranchers and potential noncompliance: "from the industry side the concern is that they do not know how the whole system will work. Their complaint is that they have not received the information. Another problem is that they get the information from fellow farmers, which is most of the time incorrect, but which influences them negatively" (senior employee, national government/ regulation and monitoring services, 2008, personal communication). This concern is mirrored by a respondent from an organization that represents the wildlife-ranching industry in South Africa: "game farmers and wildlife translocators don't take the TOPS very well-basically due to confusions, misunderstandings and complexity of the regulations" (senior representative, wildliferanching industry, 2008, personal communication).

The move to temporarily remove lion as a listed large predator has angered many people within the wildlife ranching community who feel that the original purpose of the regulations has been removed. The removal has consequently intensified the debate surrounding the regulations, and late changes such as this have contributed to the implementation of the regulations having a troubled start. Many ranchers also feel that they have a greater knowledge of managing wildlife than those within government because of their practical experience. Those within conservation NGOs appear generally positive about the new regulations, although some feel that they do not fully address the problems of the industry, and there is widespread concern that their implementation will not be adequate. Wildlife consultants again generally view the regulations as being positive for conservation, but also have concerns about their policing. A lack of enforcement officials and a lack of support from the judicial system have been reported as obstacles by the national department. Wildlife consultants/ conservationists working on ranches appear to be focused on the practicalities of implementing the regulations, for example, by removing alien species, and should be a source of support to ranch owners in interpretation and implementation. As such, NGOs appear to be largely acting to bridge the gap between the local, provincial, and national groups.

\section{Economic Interests Versus Conservationist Aims}

There are concerns among those within the ranching industry that the new regulations will have an impact on their income. A key issue for ranchers appears 
to be the government move toward restrictions on the introduction of TOPS and invasive species that are not within their natural distribution range, and the effect that this may have on tourism opportunities. Some provinces, such as Gauteng, already have restrictions on extralimital species, whereas others do not. The manager of a game capture team whose livelihood is dependent upon the game he can catch and sell, commented:

\section{They don't want certain species to come into the Western Cape and they say species that weren't in the Western Cape 100 yrs ago should go out of the Western Cape or be shot there. It's people that sit in their office all day, been studying all their life, never got out of their four walls and have no idea what is going on in the world practically. In 5 yrs time, the Eastern Cape is going to get all the tourism and Cape Town nothing; there is no game around Cape Town. We have to start game farms or else we are going to lose all of our tourism. (Manager, wildlife ranching industry/game capture company, 2007, personal communication).}

In some cases, the legislation will restrict wildlife ranchers from obtaining species that are popular with tourists such as white rhino (Ceratotherium simum), giraffe, and black wildebeest, leading to what some call unfair competition where some ranchers have an advantage in terms of ability to attract wildlife-viewing tourists and hunters. The DEAT Directorate of Regulation and Monitoring Services has been investigating various options as to how to deal with the occurrence of animal species that are already present in some provinces but now prohibited. As one senior employee explained:

We are considering allowing the keeping of these species where they already occur, but prohibiting the translocation of them to other areas. If they were allowed to be imported before under legal permits, we cannot force owners to remove them now. With development of legislation, we also have to keep constitutional issues, such as ownership, in mind. (National government/ regulation and monitoring services, 2008, personal communication).

Certainly, the removal of these species would be a considerable challenge that would affect a large number of ranchers. For example, a study in the
Eastern Cape reported that six out of the 10 private game reserves surveyed had giraffe, totalling 104 giraffe, despite evidence that they do not naturally occur in the Eastern Cape and damage vegetation (Langholtz and Kerley 2006). The impact of the regulations will vary among ranches and provinces depending on the type of wildlife utilization, for example, hunting or wildlife viewing. This impact is also affected by distance from cities and the type of habitat and species present (Bothma et al. 2009). Gaining permits for species that ranchers regularly bought in the past may now be difficult. For example, Sanbona Wildlife Reserve, situated in the Western Cape, will no longer be able to bring in black wildebeest as they did not occur there historically. However, Sanbona Wildlife Reserve is currently in the process of joining up with the CapeNature stewardship program, and in doing so will be given provincial reserve status and, along with this, certain benefits including extra time to implement the new TOPS legislation. Stewardship could be an option for some ranchers with biologically important land, and could be encouraged by offering incentive-based mechanisms for landowners who enter into agreements to conserve biodiversity on their land. However, opportunities are limited as programs concentrate their resources in areas threatened by land transformation. Furthermore, most ranches occur in savannah areas, which are not the highest priority for stewardship type arrangements (resource ecologist for the stewardship program, 2007, personal communication).

A further concern for ranchers is the level of resources needed to remove alien and invasive plant species. Those respondents within conservation NGOs and provincial governments also have concerns regarding the level of motivation of ranchers to do more to conserve their land. Indeed, a number of ranchers felt that they were already helping the government by maintaining natural areas, and that conservation should be the responsibility of the government and not impact on their livelihoods. It was widely suggested by respondents that support and economic incentives such as tax rebates would be needed in addition to legislation to motivate ranchers. For example, one provincial government representative (2007, personal communication) commented that: "in the majority of cases, ranchers will only be interested in doing more if a benefit can be translated to monetary value, which is seldom possible." 
Incentives for ranchers to form conservancies were also suggested. However, according to an interviewee from a well-known conservation NGO (2007, personal communication), "in most provinces private game ranchers are not being offered any assistance or incentive to do more in terms of conservation." In Gauteng, for example, tax incentives have been mentioned but not yet implemented. The Gauteng government do provide support, but in the form of an extension service to the public that promotes best practices regarding the use of natural resources and wildlife, and a telephone helpline and information regarding conservation priorities for the province. Ecological decision support is delivered free of charge when land has been prioritized as important for conservation purposes. In the North West province, supporting private conservation initiatives is not currently a priority. Their immediate concern is "investigating the possibility of introducing previously disadvantaged people into the gamefarming industry" (provincial government representative, 2007, personal communication).

A further concern of ranchers is the increased cost of permits under the new regulations. In addition, a member of a game-capture team expressed concern that the new regulations would slow down the permit system, thereby losing them time and money. The South African Predator Breeders Association (SAPBA) is among those in opposition because of economic concerns. The South African Predator Breeders Association represents those farmers who are making a living by breeding lions for hunting. They have instituted legal proceedings against the Minister of Environmental Affairs because of the clause in the TOPS regulations that captive-bred lions may not be hunted for a period of 24 months after release, which they consider to be detrimental to their business and income. Recently (June 2009), a court upheld the TOPS regulations and, consequently, lion will be again added to the TOPS list. This ruling will affect some 123 breeders and approximately 3,000-4,000 lions currently in breeding facilities. An estimated $80 \%-90 \%$ of lions hunted in South Africa are believed to be canned (Patterson and Khosa 2005, Lindsey at al 2007).

\section{CONCLUSION}

Although positive conservation impacts are attributed to private wildlife ranching in South Africa, self-regulation appears to have been largely unsuccessful, as there are a growing number of unwanted ecological consequences associated with ranching that countermand South Africa's international and national obligations on biodiversity conservation and the sustainable use of wildlife. New national regulations are "scaling-up" the regulation of the wildlife industry with the aim of coordinating provincial legislation and steering the industry in a more conservationist direction.

The new regulations will begin to address international and national obligations by potentially combating a number of specific ecological problems associated with wildlife ranching such as genetic pollution, and through greater species monitoring and improved accuracy in setting hunting quotas. However, in practice, the regulations are a significant source of tension among stakeholders at different sociopolitical scales (Hein et al. 2006) and will be challenging to implement and enforce. Competing agendas and differing levels of power and capacities among different interest groups at various levels, from local to international, add to the complexities of regulating wildlife and present significant challenges to environmental governance (Jones 2006). The scale and diversity of the organizations within the ranching industry also make regulation fraught with difficulty. Despite the process of public consultation, feedback, workshops, and information sessions in the development of the regulations, there is disagreement regarding the content of the regulations, there are tensions among stakeholders regarding the political scale at which it is appropriate to regulate the industry, and also regarding the suitability of ecological knowledge at various levels to best regulate and manage ranches. There are also major concerns regarding the capacity to implement and enforce the regulations and the willingness of ranchers to comply.

Ranchers are largely concerned about the impact that the regulations may have on their livelihoods, particularly with regard to a potential reduction in tourism revenues from restrictions in use, and increased costs because of additional permits. These concerns should be taken seriously, as any regulations reducing or removing the incentive to ranch wildlife may impair the relative competitiveness of wildlife as a land use, thus threatening the survival of the industry. As previously stated, the success of conservation on these lands is said to be based on the price-proprietorship-subsidiarity hypothesis (Child 2003, 2005). However, the new 
regulations appear to countermand these principles by potentially reducing the value of wildlife to ranchers. Therefore, in addressing these problems at the margin, the new regulations may actually encourage some ranchers to convert their land away from conservation-friendly land use. Furthermore, the regulations countermand this hypothesis by organizing wildlife at a national, rather than a local, level. However, according to Murphree (2000) and Lovell et al. (2002), the "big government" and "small is beautiful" approaches to conservation both have inherent problems in dealing with scale. For example, large jurisdictions can lack transparency with their constituents, be out of touch with local priorities and aspirations (Lovell et al. 2002), and lack linkages between authority and responsibility (Murphree 2000). Alternatively, "small is beautiful" can result in a multiplicity of fragmented jurisdictions that lack coordination when it comes to addressing large-scale problems (Lovell et al. 2002). According to Berkes (2004), it is important to match the scale of management to the scale of the system to be managed. It may be that integrating approaches offers the best solution, combining locally tailored support with a framework of national monitoring and quota setting to achieve a widespread reduction in ecological consequences, while providing for local variance. This will require a shared vision across all institutional levels that will depend on gaining the support of wildlife ranchers and individuals within provincial governments.

Innovative strategies will be necessary to reduce costs and gain support, including increased assistance for wildlife ranchers in the form of tax rebates for improved ecological performance, and extension services in conjunction with ecological advice from provincial governments. These measures would be valuable and may increase ranchers' motivation and cooperation to adopt environmentally friendly practices, with the emphasis on long-term ecological health rather than short-term gain (Langholz and Kerley 2006). Further, wildlife ranchers should explore stewardship options, even if they are limited in availability, species-focused support available from the EWT working groups, and ecological management services in their province. In some cases, ecological services are offered for free, with international volunteers assisting in funding the work (Cousins et al. 2009). A number of authors (including Langholz and Kerley 2006, Lindsey et al. 2007) have suggested the development of a nationally recognized certification or rating system based on factors such as commitment to conservation including the creation of conservancies, community development, and hunting ethics. Such a system may create a market-driven desire for sustainable practices, rather than just use. It will be important that those at the various sociopolitical levels work closely together and that there is an ongoing system of feedback. The importance of the creation of incentives that support conservation and sustainable use, and the provision of greater human capacity to conserve and manage biodiversity, are encompassed in national policy goals and need to be addressed as a matter of urgency. In addition, greater public education may reduce the pressure on ranchers to stock specific species favoured by tourists in what is an incentive-led industry.

In conjunction with efforts to support and motivate good conservation practice on private wildlife ranches, important issues such as community involvement and land reform must to be taken into consideration. The new TOPS regulations do go some way to enhancing opportunities for entrance into the game-ranching industry for previously disadvantaged individuals, by stipulating that registered hunting organizations must have a clear policy to include persons from disadvantage communities as members. The future of conservation in South Africa depends on developing innovate strategies that are not only ecologically appropriate, but also economically viable for ranchers, and socially just for previously disadvantaged communities. Achieving all three will be challenging, but is vital for the continued growth and success of private wildlife ranching and conservation in South Africa.

Responses to this article can be read online at: http://www.ecologyandsociety.org/volXX/issYY/artZZ/ responses/

\section{Acknowledgments:}

The research for this paper was funded by a PhD scholarship in GEES at the University of Birmingham and an NERC/ESRC grant

PTA-036-20-06-00017. The authors wish to thank all those who gave their time to be interviewed and two anonymous reviewers for their insightful comments. 


\section{LITERATURE CITED}

Adams, J. S., and T. O. McShane. 1996. The myth of wild Africa: conservation without illusion. University of California Press, Berkeley, California, USA.

Adams, W., and M. Mulligan, editors. 2003. Decolonising nature: strategies for conservation in a postcolonial era. Earthscan, London, UK.

Amalgamated Banks of South Africa (ABSA) Group Economic Research. 2003. Game ranch profitability in southern Africa. The SA Financial Sector Forum, Rivonia, South Africa.

Berkes, F. 2004. Rethinking community-based conservation. Conservation Biology 18(3):621630.

Bigalke, R. C. 2000. Functional relationships between protected and agricultural areas in South Africa and Namibia. Pages 169-201 in H. H. T. Prins, J. G. Grootenhuis, and T. T. Dolan, editors. Wildlife conservation by sustainable use. Kluwer Academic Publishers, Boston, Massachusetts, USA.

Boone, R. B., and N. T. Hobbs. 2004. Lines around fragments: effects of fencing on large herbivores. African Journal of Range and Forage Science $\mathbf{2 1}$ (3):147-158.

Botha, M. A. 2001. Incentives for conservation on private land: options and opportunities. Cape Conservation Unit Report 02/2001, Botanical Society of South Africa, Cape Town, South Africa.

Bothma, J. du P. 2002. Game ranch management. Fourth edition. Van Schaik, Pretoria, South Africa.

Bothma, J. du P., H. Suich, and A. Spenceley. 2009. Extensive wildlife production on private land in South Africa. Pages 163-184 in H. Suich, B. Child, and A. Spenceley, editors. Evolution and innovation in wildlife conservation-parks and game ranches to transfrontier conservation areas. Earthscan, London, UK.

Bürgener, M., N. Snyman, and M. Hauck. 2001. Towards a sustainable wildlife trade: an analysis of nature conservation legislation in South Africa with particular reference to the wildlife trade. Institute of Criminology, University of Cape Town, Cape Town, South Africa.

Bürgener, M., A. Greyling, and A. Rumsey. 2005. Status quo report on the policy, legislative and regulatory environment applicable to commercial and recreational hunting in South Africa. Background research paper for the Panel of Experts. Department of Environmental Affairs and Tourism (DEAT), Johannesburg, South Africa.

Carroll, T., and M. Boshoff. 2007. Guidelines for the implementation of threatened or protected species (TOPS) regulations and the issuance of TOPS permits in terms of the National Environmental Management: Biodiversity Act (Act 10 of 2004) (NEMBA). Republic of South Africa, Cape Town, South Africa.

Carruthers, J. 2008. "Wilding the farm or farming the wild?" The evolution of scientific game ranching in South Africa from the 1960s to the present. Transactions of the Royal Society of South Africa 63(2): 160-181.

Castley, J. G., A. F. Boshoff, and G. I. H. Kerley. 2001. Compromising South Africa's natural biodiversity-inappropriate herbivore introductions. South African Journal of Science 97:344-348.

Child, B. 2003. When biodiversity meets humanity. Nature 421:113-114.

Child, B. 2005. Principles, practice, and results of CBNRM in southern Africa. Pages 17-50 in M. W. Lyman and B. Child, editors. Natural resources as community assets: lessons from two continents. Sand County Foundation and the Aspen Institute. Madison, Wisconsin, USA.

Child, B. 2009. Private conservation in southern Africa: practice and emerging principles. Pages 103-111 in H. Suich, B. Child, and A. Spenceley, editors. Evolution and innovation in wildlife conservation-parks and game ranches to transfrontier conservation areas. Earthscan, London, UK.

Cope, M. 2005. Coding transcripts and diaries. Pages 445-459 in N. Clifford, and G. Valentine, editors. Key methods in geography. Sage Publications, London, UK. 
Cousins, J. A., J. P. Sadler, and J. Evans. 2008. Exploring the role of private wildlife ranching as a conservation tool in South Africa: stakeholder perspectives. Ecology and Society 13(2): 43. [online] URL: http://www.ecologyandsociety.org/voll3/ iss $2 / \operatorname{art} 43 /$.

Cousins, J. A., J. Evans, and J. P. Sadler. 2009. Selling conservation? Scientific legitimacy and the commodification of conservation tourism. Ecology and Society 14(1): 32. [online] URL: http://www.e cologyandsociety.org/vol14/iss1/art32/.

Department of Environmental Affairs and Tourism (DEAT). 1997. White paper on the conservation and sustainable use of South Africa's biological diversity. Notice 1095 of 1997. DEAT, Pretoria, South Africa.

Department of Environmental Affairs and Tourism (DEAT). 2005. Panel of experts on professional and recreational hunting in South Africa. Report to the Minister of Environmental Affairs and Tourism. DEAT, Pretoria, South Africa.

Department of Environmental Affairs and Tourism (DEAT). 2007a. National Environmental Management: Biodiversity Act, 2004: publication of lists of critically endangered, endangered, vulnerable and protected species. Government Gazette Number 29657 (23 February 2007). DEAT, Pretoria, South Africa. [online] URL: http://www.S peciesstatus.sanbi.org/pdf/NEMBAToPslist23Feb.pdf

Department of Environmental Affairs and Tourism (DEAT). 2007b. Threatened and Protected Species Regulations (TOPS). National Environmental Management: Biodiversity Act (10/2004): Threatened or Protected Species Regulations. DEAT, Pretoria, South Africa.

Department of Environmental Affairs and Tourism (DEAT). 2009a. National Environmental Management: Biodiversity Act, 2004: list 3: list of invasive species in terms of section 70. Government Gazette Number 32090 (3 April 2009). DEAT, Pretoria, South Africa. [online] URL: http://www.i nfo.gov.za/view/DownloadFileAction?id=98583.

Department of Environmental Affairs and Tourism (DEAT). 2009b. National Environmental Management: Biodiversity Act, 2004: draft alien and invasive species regulations (AIS), 2009. Government Gazette Number 32090 (3 April 2009). DEAT, Pretoria, South Africa. [online] URL: http:/ /www.environment.gov.za/HotIssues/2009/invsvSpecies/ alienInvsvSpecies03042009.pdf.

Dunn, K. 2005. Interviewing. Pages 79-105 in I. Hay, editor. Qualitative research methods in human geography. Oxford University Press, UK.

Fontana, A., and J. H. Frey. 2005. The interview: from neutral stance to political involvement. Pages 695-727 in N. K. Denzin, and Y. S. Lincoln, editors. The SAGE handbook of qualitative research methods. Third edition. Sage Publications, Thousand Oaks, California, USA.

Green, W. C. H., and A. Rothstein. 1998. Translocation, hybridization and the endangered black-faced impala. Conservation Biology 12 (2):475-480.

Hall-Martin, A. J., and J. G. Castley. 2003. The status of the black and white rhinoceros on private land in South Africa. Pachyderm 34:24-32.

Hamman, K., S. Vrahimis, and H. Blom. 2003. Can current trends in the game industry be reconciled with nature conservation? African Indaba 1(5):3-6.

Hamman, K. C. D., P. H. Lloyd, and J. C. Stadler. 2005. Hunting as an acceptable management tool for conservation. Submission to the panel of experts. Department of Environmental Affairs, Pretoria, South Africa.

Harris, F. 2004. Conserving biodiversity resources. Pages 95-114 in F. Harris, editor. Global Environment Issues. Wiley, Chichester, UK.

Hearne, J., and M. McKenzie. 2000. Compelling reasons for game ranching in Maputoland. Pages 417-438 in H. H. T. Prins, J. G. Grootenhuis, and T. T. Dolan, editors. Wildlife conservation by sustainable use. Kluwer Academic Publishers, Dordrecht, The Netherlands.

Hein, L., K. van Koppen, R. S. de Groot, and E. C. van Ierland. 2006. Spatial scales, stakeholders and the valuation of ecosystem services. Ecological Economics 57:209-228. 
Jones, S. 2006. A political ecology of wildlife conservation in Africa. Review of African Political Economy 33(109):483-495.

King, B. H. 2007. Conservation and community in the new South Africa: a case study of the Mahushe Shongwe Game Reserve. Geoforum 38:207-219.

Krug, W. 2002. Private supply of protected land in southern Africa: a review of markets, approaches, barriers and issues. Report to Environment Directorate. Organisation for Economic Cooperation and Development (OECD), Paris, France.

Langholz, J. A., and G. I. H. Kerley. 2006. Combining conservation and development on private lands: an assessment of ecotourism-based private game reserves in the Eastern Cape. Report Number 56. Centre for African Conservation Ecology, Nelson Mandela Metropolitan University, Port Elizabeth, South Africa.

Leader Williams, N., S. Milledge, K. Adcock, M. Brooks., A. Conway, M. Knight, S. Mainka, E. B. Martin, and T. Teferi. 2005. Trophy hunting of black rhino Diceros bicornis: proposals to ensure its future sustainability. Journal of International Wildlife Law and Policy 8:1-11.

Lindsey, P. A., J. T. du Toit, and M. G. L. Mills. 2005. Attitudes of ranches towards African wild dogs Lycaon pictus: conservation implications on private land. Biological Conservation 125:113121.

Lindsey, P. A., L. G. Frank, R. Alexander, A. Mathieson, and S. S. Romañach. 2006. Trophy hunting and conservation in Africa: problems and one potential solution. Conservation Biology 21 (3):880-883.

Lindsey, P. A., P. A. Roulet, and S. S. Romañach. 2007. Economic and conservation significance of the trophy hunting industry in sub-Saharan Africa. Biological Conservation 134:455-469.

Lindsey, P. A., S. S. Romañach, and H. T. DaviesMostert. 2009. The importance of conservancies for enhancing the value of game ranch land for large mammal conservation in southern Africa. Journal of Zoology 227:99-105.

Longhurst, R. 2005. Semi-structured interviews and focus groups. Pages 117-132 in N. Clifford, and
G. Valentine, editors. Key methods in geography. Sage Publications, London, UK.

Lovell, C., A. Mandondo, and P. Moriarty. 2002. The question of scale in integrated natural resource management. Conservation Ecology 5(2):25.

MacKenzie, J. 1988. The empire of nature: hunting, conservation and British imperialism. Manchester University Press, Manchester, UK.

Marshall, C., and G. B. Rossman. 1995. Designing qualitative research. Sage Publications, Thousand Oaks, California, USA.

Murphree, M. W. 2000. Boundaries and borders: the question of scale in the theory and practice of common property management. Eighth Conference of the International Association for the Study of Common Property Bloomington, Indiana, USA.

Neumann, R. 1996. Dukes, earls and ersatz Edens: aristocratic nature preservationists in colonial Africa. Environment and Planning D: Society and Space 14:79-98.

Patterson, C., and P. Khosa. 2005. A status quo study on the professional and recreational hunting industry in South Africa. Report to the Minister of Environmental Affairs and Tourism, Panel of Experts on Professional and Recreational Hunting in South Africa. DEAT, Pretoria, South Africa.

Scriven, L., and T. Eloff. 2003. Markets derived from nature tourism in South Africa and KwaZuluNatal: a survey of the sale of live game. Pages 245286 in B. Aylward, and E. Lutz, editors. Nature tourism, conservation and development in KwaZulu-Natal, South Africa. World Bank, Washington, D.C., USA.

Secretariat of the Convention on Biological Diversity. 2001. Handbook of the convention on biological diversity. Earthscan, London, UK.

Smith, N., and S. L. Wilson. 2002. Changing land use trends in the thicket biome: pastoralism to game farming. Report Number 38. Terrestrial Ecology Research Unit, University of Port Elizabeth, Port Elizabeth, South Africa.

Steenkamp, C., D. Marnewick, and K. Marnewick. 2005. A status quo of the conservation impacts from the professional and recreational 
hunting industry. Report to Minister of Environmental Affairs and Tourism, Panel of Experts on Professional and Recreational Hunting in South Africa. Republic of South Africa, Pretoria, South Africa.

Strauss, A., and J. Corbin. 1990. Basics of qualitative research: grounded theory procedures and techniques. Sage Publications, London, UK.

Wynberg, R. 2002. A decade of biodiversity conservation and use in South Africa: tracking progress from the Rio Earth Summit to the Johannesburg World Summit on sustainable development. South African Journal of Science 98:233-243. 
APPENDIX 1. TOPS regulations: key points relating to conservation and wildlife ranching

(1) Issuing authorities considering a permit application for a TOPS species have to take into account a number of factors, including: the International Union for Conservation of Nature (IUCN) Red List for Threatened Species status, whether the restricted activity in respect of which the application is submitted is likely to have a negative impact on the survival of the relevant listed threatened or protected species, the biodiversity management plan for the species concerned, if any, relevant information on the database that the South African National Biodiversity Institute (SANBI) is required to keep in terms of section 11 (1)(j) of the National Environmental Management: Biodiversity Act (NEMBA), and any risk assessment or expert evidence requested by the issuing authority (Regulation 10).

(2) Applications involving wild populations of critically endangered species require additional measures, including: (1) a risk assessment, and (2) consideration as to whether the restricted activity applied for is in line with the biodiversity management plan for the species involved (Regulation 11).

(3) Additional factors to be taken into account by issuing authorities when considering applications for hunting permits include: the hunting off-take limits determined by SANBI for a listed threatened or protected animal species (Regulation 12).

(4) In the case of a damage-causing animal originating from a protected area, a standard set of control options must be considered by the relevant provincial department. A damage-causing animal may only be killed without a permit in self-defence where human life is threatened (Regulation 14).

(5) An issuing authority must refuse a permit application for the translocation of a specimen of a listed threatened or protected species to an extensive wildlife system: (1) if such an extensive wildlife system falls outside the natural distribution range of that animal species and the extensive wildlife system is a protected area, or (2) if there is a risk of transmitting disease or of hybridization with other species in that extensive wildlife system (Regulation 23).

(6) Prohibited activities now include the hunting of a listed large predator, white or black rhinoceros (Ceratotherium simum or Diceros bicornis), that is a put-and-take animal or in a controlled environment, that is, "canned" hunting $\dagger$ and the use of any tranquilizing agents or use of a gin trap (Regulation 24).

(7) Prohibited activities involving listed threatened or protected Encephalartos species include: gathering, cutting, destroying, and trade in artificially propagated specimens of critically endangered or endangered Encephalartos species or the export of such specimens, with a stem diameter of more than $15 \mathrm{~cm}$, except where provided for in a biodiversity management plan approved by the Minister in terms of section 43 of the Biodiversity Act (Regulation 25; amended 27 February 2009).

(8) Dart or "green" hunting $\neq$ is now prohibited except in cases where a veterinarian or a person authorized by a veterinarian in writing is in possession of valid permit (Regulation 26).

(9) Bow hunting of a listed large predator, crocodile (Crocodilus, white and black rhinoceros, and elephant (Elephas) is now prohibited (Regulation 26).

(10) Compulsory conditions for the registration of captive breeding operations: the person to whom the registration certificate is granted must prevent hybridization and/or inbreeding, keep a stud book where appropriate, and provide information each year to the issuing authority (Regulation 35; also see Appendix 2).

(11) A Scientific Authority has been established that will meet at least once a year to develop a report to 
the Minister regarding compliance with provisions in terms of section 61 of the Biodiversity Act (Regulations 59/65).

$\dagger$ Green hunting is where animals are hunted by means of a dart containing an immobilizing agent.

\$Canned hunting is where lions are bred and hunted within in a controlled, caged environment for commercial purposes. 
APPENDIX 2. Draft Alien and Invasive Species Regulations: summary of key points relating to conservation and wildlife ranching

(1) A person who is the owner of land where a specimen of a prohibited alien species or a listed invasive species occurs, and does not have a permit, must notify the relevant competent authority in writing (Regulation 18[1]). ***is the meaning of this sentence still correct?

(2) Restricted activities: allowing any specimen of an alien or listed invasive species to grow, breed, or multiply; allowing the movement or spread of a specimen of an alien of listed invasive species; and releasing a specimen of an alien or listed invasive species (Regulation 22).

(3) A person may not import into the Republic of South Africa a specimen of any species, including an exempted species, unless authorized to do so by a permit (Regulation 24[1]).

(4) A person may not release a specimen of a new alien species imported into the Republic of South Africa unless authorized to do so by a permit (24[2]).

(5) A person may undertake any restricted activity involving a specimen of an exempted species without a permit, except import into the Republic of South Africa (Regulation 25[1/2]).

(6) A person may not import nor undertake any other restricted activity involving a specimen of a prohibited alien species (Regulation 26).

(7) A person may not undertake the following restricted activities involving a specimen of a species listed in List 3 as an invasive requiring compulsory control: import, possess, allow to grow, breed, translocate, trade/dispose, buy/acquire (Regulation 27[1]).

(8) No person may undertake the following restricted activities involving a specimen listed in List 3 as an invasive species controlled by the invasive species management program: import, breed, translocate, allow spread, sell/dispose, buy/acquire (Regulation 28).

(9) No person may undertake the following restricted activities involving a specimen of a species listed in List 3 as an invasive species controlled by area without a demarcation permit: import, possess, allow to grow/breed/multiply, translocate, sell/dispose, buy/acquire (Regulation 29[1]). However, a person may carry out a restricted activity without a permit in the part of the Republic of South Africa indicated as the distribution range of the species or an area demarcated for that purpose (a person must apply for demarcation) $(29[3 / 30][1 / 2])$.

(10) No person may undertake the following activities involving specimen of a species listed in List 3 as a species controlled by activity without a permit: import, possess, allow to grow/breed/multiply, transloctate, sell/dispose, buy/acquire (31[1]).

(11) A person disposing of immovable property is obliged to disclose to the person acquiring the property whether there are any prohibited alien or prohibited invasive species or any invasive species controlled by the invasive species management program on the property (34[1]).

(12) A risk assessment must be undertaken before: carrying out an activity prescribed in terms of Regulation 23, importing a specimen of any species described in Regulation 24 into the Republic of South Africa, demarcating an area in terms of Regulation 30, and issuing a permit to undertake any other restricted activity involving a listed invasive species (Regulation 35). 
(13) A risk assessment must be conducted at the cost of the applicant (Regulation 40).

(14) Upon receipt of an application for a permit, the issuing authority must take into consideration the national strategy, and the contents of the risk assessment report (44[2]).

(15) An issuing authority must refuse an application if there is a risk that the restricted activity could result in a significant impact on biological diversity (44[4]).

(16) A competent authority must keep a record of all directives issued along with further information (Regulation $71[\mathrm{a} / \mathrm{b}]$ ) and, at the end of each calendar year, submit a written report of all directives and further information recorded to SANBI (71[c]).

(17) The Department of Environmental Affairs and Tourism must prepare a national strategy for preventing, eradicating, or controlling alien and listed invasive species (7[1]).

(18) The Department of Environmental Affairs and Tourism must develop an invasive species management program for each species identified (8[1]). A competent authority may require a landowner to prepare a plan for the monitoring, control, and eradication of invasive species occurring on their land $(9[3])$.

(19) The Institute (SANBI) must develop and publish guidelines for the preparation of an invasive species control plan on its website (9[1]).

(20) The Institute (SANBI) must establish and maintain a national register of alien and listed invasive species and control plans (Regulation 10) and submit a report on their status to the Minister (Regulation 12). 
APPENDIX 3. Further respondents' comments regarding the implementation and enforcement of TOPS regulations

Resistance from game ranchers. The reason is that many of them are still uninformed, or misinformed. In many cases the use of TOPS permits will make it easier, but that is not understood by game ranchers. The misperception by farmers is that they will not be able to do anything with their TOPS species, which is not true. However, now they need a permit for any activity, where previously it was not always necessary in terms of provincial legislation. A reality is that they will have to pay for all the permits and the registration, which will increase the costs of the total amount of permits they will need and they will need to pay for more of them. (Senior employee, national government/regulation and monitoring services, 2008, personal communication)

Game-farm owners with TOPS species may register their game farms. Only once registered, they may apply for a standing permit. This permit is valid for 3 yrs, and may list all the activities that may be undertaken for the general management of the farm (includes activities such as hunting, selling, buying, transporting, darting for treatment, importing, exporting, capturing, etc.). The standing permit may also list the TOPS species on the game farm. In terms of provincial legislation, the same type of permit is issued (called an exemption permit) but only for hunting, capturing, and selling. Therefore, the standing permit will include more activities. Also, if they apply correctly, they only need to apply for a permit once in 3 yrs, where previously they had to apply in many cases, for permits on an individual basis. In addition, only when registered, the game-farm owner may purchase a book with "game-farm hunting permits" that he may issue to each hunter that will hunt a TOPS species on the farm, rather than the hunter applying to nature conservation and having to wait 3 weeks plus. So it is easier. (Senior employee, national government/regulation and monitoring services, 2008, personal communication)

Our national department arranged an information session in all the provinces last year. We informed the provincial offices about the session, and they had to inform the stakeholders, as up to now we have not dealt with the industries directly. Unfortunately, the attendance in many provinces was poor to extremely poor. We also compiled a guidelines document for distribution on how to interpret the legislation, how to issue permits, and what the permits could be used for. (Senior employee, national government/regulation and monitoring services, 2008, personal communication)

I am confident that in time we will be able to effectively enforce the TOPS regulations. But it will largely depend on the willingness and capability of provinces to do their share. From the national department side we will sort out the impractical provisions which unfortunately will take time, as we have to amend the Biodiversity Act. Conservation authorities should make an effort to appoint adequate numbers of properly trained law enforcement officials that will do proactive, rather than reactive, law enforcement, i.e., patrolling problem areas on a regular basis. The other problem with successfully charging people operating illegally is the lack of support from the judicial system. Hopefully in terms of national legislation, with proper fines, this problem should be sorted out. (Senior employee, national government/regulation and monitoring services, 2008, personal communication)

We provided an implementation guideline document, to explain how the permits work, what they can be used for, how to interpret the regulations, etc. Unfortunately, officials do not read this document and still provide wrong information to the public, or prefer to direct their questions to us before looking at what the guidelines say. (Senior employee, national government/regulation and monitoring services, 2008, personal communication)

(Regarding implementation) Lack of finances and personnel will definitely play a role, but provincial departments have had a period of about 2 yrs to prepare for the implementation, to plan their personnel structure, and to budget for that. It did not happen. (Senior employee, national government/regulation 
and monitoring services, 2008, personal communication)

Major concerns regarding implementation and enforcement are willingness and readiness of the provinces to implement in terms of human resources, finances, expertise because of continuity of personnel/high turnover, knowledge and understanding of the regulations, lack of managerial/technical/ scientific support in decision making, poor planning, tensions, and lack of communication between provincial offices and wildlife ranchers, lack of resources for properly trained enforcement officials, and lack of support from the judicial system. (Senior employee, national government/regulation and monitoring services, 2008, personal communication)

We (provincial authorities) sometimes differ from some individuals at national because of our many yrs hands-on experience in the provinces, and their lack thereof. Many ideas might have originated from persons not familiar with the bigger picture or possibly with hidden agendas or even negative attitudes such as the so-called "greenies." Not all decisions taken were done on scientific proof, and some were just humanly impossible to implement. Unfortunately, the provinces have to implement. We were sufficiently consulted in the forming of the regulations, but sometimes we were overridden by who knows who. (Provincial government representative, 2008, personal communication)

In short, we will have to handle many more applications, do inspections for each application, process and issue the permits, and follow up with law enforcement. No additional funding has been provided. (Provincial government representative, 2008, personal communication)

There is a dispute between the official nature conservation agencies and the private game farmers because the former is the regulator and the latter does not want to be regulated. This is the crux of the debate. (Provincial government representative, 2007, personal communication)

Provincial authorities differ in opinion from national and there are prescripts that we will have to implement, although we do not agree with national. Provincial authorities were not capacitated to implement and lack either funding, personal skills, or equipment. (Provincial government, 2008, personal communication)

(Are you confident that the new TOPS legislation can be implemented and enforced effectively?) No. National does not have the capacity or skills. Provincial neither. (Provincial government represenative, 2008, personal communication

The TOPS regulations will go a long way in protecting the listed species, but it is to some extent restrictive to landowners and will be costly and difficult to implement. Legislation and regulations should facilitate conservation on private land and not be too restrictive or difficult to implement. That is where we must still find the balance. (Provincial government representative, 2007, personal communication)

Budget and staff constraints are the major stumbling blocks. (Provincial government representative, 2007, personal communication)

Conservation on private land could be improved by conservation initiatives, increased government extension services, and the streamlining of legislation and permitting procedures. Incentives from government, for example, tax rebates for conservation efforts, would assist in private conservation initiatives. (Provincial government representative, Northern Cape, 2007, personal communication)

New, good and, I suspect, impossible to implement in Africa at the present time. (Conservation NGO representative, 2007, personal communication)

As with all legislation, its implementation is crucial and this is grossly inadequate. (Conservation NGO representative, 2007, personal communication) 
Ranches need support in the form of financial incentives, for example, tax rebates, management assistance, help with clearing alien and invasive plants, particularly in the case if habitats and species that are not money spinners. Building positive relationships with landowners. (Conservation NGO/ conservation coordinator, 2007, personal communication)

Lions caused the whole big upset and it is the hunting of lions that is the problem, not the other species that is now affected. The two species that really required protection (lions and cycads) have now been excluded. I'm not against TOPS and fully support the original purpose. (Senior representative, wildlife ranching industry, 2008, personal communication)

There is a lack of government officials who can adequately implement these regulations. At the moment, our national department is very positive while almost all nine provinces are not equipped, trained, or motivated to implement the regulations. (Wildlife ranching representative, 2008, personal communication)

It is very obvious that the provinces don't know what is going on 2 weeks before implementation. To add to that, the second set of application forms have now also been withdrawn, we are again waiting for the final application forms. Unbelievable! (Wildlife ranching representative, 2008, personal communication)

Looking at it from a conservationist point of view, the regulations are a good thing. The only problem I foresee is the policing of this in the beginning. A problem in South Africa regarding not just these new regulations is manpower and, also very importantly, expertise. (Wildlife manager/conservationist on private reserve, 2008, personal communication)

(Speaking about a stewardship scheme.) In Sanbona's case, we can have giraffe and white rhino for $x$ amount of years to improve tourism. After this time, or for example, if we get any black rhino (Diceros bicornis), we have to take them off and then follow the new regulations in the future. It is important to note that although these new regulations seem strict, the governing bodies will still work closely with the people involved. (Wildlife manager/conservationist, 2008, personal communication

Looking at alien species already occurring in certain areas, this is going to be very difficult and going to take a long time to take off. (Wildlife manager/conservationist on private reserve, 2008, personal communication) 